\title{
Diagnostic performance of non-invasive imaging for stable coronary artery disease: A meta-analysis
}

\author{
Gianluca Pontone ${ }^{\mathrm{a}, *}$, Andrea I. Guaricci ${ }^{\mathrm{b}, 1}$, Suetonia C. Palmer ${ }^{\mathrm{c}}$, Daniele Andreini ${ }^{\mathrm{a}, \mathrm{d}}$, Massimo Verdecchia ${ }^{\mathrm{a}}$, \\ Laura Fusini ${ }^{a}$, Valentina Lorenzoni ${ }^{\mathrm{e}}$, Marco Guglielmo ${ }^{\mathrm{a}}$, Giuseppe Muscogiuri ${ }^{\mathrm{a}}$, Andrea Baggiano ${ }^{\mathrm{a}}$, \\ Mark G. Rabbat ${ }^{\mathrm{f}, \mathrm{g}}$, Filippo Cademartiri ${ }^{\mathrm{h}}$, Giovanni F. Strippoli ${ }^{\mathrm{i}, \mathrm{j}, \mathrm{k}}$ \\ a Centro Cardiologico Monzino IRCCS, Milan, Italy \\ b Institute of Cardiovascular Disease, Department of Emergency and Organ Transplantation, University Hospital "Policlinico" of Bari, Bari, Italy \\ c Department of Medicine, University of Otago Christchurch, Christchurch, New Zealand \\ d Department of Cardiovascular Sciences and Community Health, University of Milan, Milan, Italy \\ e Istituto di Management, Scuola Superiore Sant'Anna, Pisa, Italy \\ ${ }^{\mathrm{f}}$ Loyola University of Chicago, Chicago, IL, USA \\ ${ }^{g}$ Edward Hines Jr. VA Hospital, Hines, IL, USA \\ h SDN IRCCS, Naples, Italy \\ ${ }^{i}$ Department of Emergency and Organ Transplantation, University of Bari, Italy \\ j School of Public Health, University of Sydney, Australia \\ ${ }^{\mathrm{k}}$ Diaverum Medical Scientific Office, Lund, Sweden
}

\section{A R T I C L E I N F O}

\section{Article history:}

Received 27 June 2019

Received in revised form 6 September 2019

Accepted 25 October 2019

Available online 6 November 2019

\section{Keywords:}

Meta-analysis

Coronary artery disease

Non-invasive test

Diagnostic pathway

Fractional flow reserve

\begin{abstract}
A B S T R A C T
Background: To determine diagnostic performance of non-invasive tests using invasive fractional flow reserve (FFR) as reference standard for coronary artery disease (CAD).

Methods: Medline, Embase, and citations of articles, guidelines, and reviews for studies were used to compare non-invasive tests with invasive FFR for suspected CAD published through March 2017.

Results: Seventy-seven studies met inclusion criteria. The diagnostic test with the highest sensitivity to detect a functionally significant coronary lesion was coronary computed tomography (CT) angiography [88\%(85\%$90 \%)]$, followed by FFR derived from coronary CT angiography $\left(\mathrm{FFR}_{\mathrm{CT}}\right)[85 \%(81 \%-88 \%)]$, positron emission tomography (PET) [85\%(82\%-88\%)], stress cardiac magnetic resonance (stress CMR) [81\%(79\%-84\%)], stress myocardial CT perfusion combined with coronary CT angiography [79\%(74\%-83\%)], stress myocardial CT perfusion [77\%(73\%-80\%)], stress echocardiography (Echo) [72\%(64\%-78\%)] and stress single-photon emission computed tomography (SPECT) [64\%(60\%-68\%)]. Specificity to rule out CAD was highest for stress myocardial CT perfusion added to coronary CT angiography [91\%(88\%-93\%)], stress CMR [91\%(90\%-93\%)], and PET [87\%(86\%-89\%)]. Conclusion: A negative coronary CT angiography has a higher test performance than other index tests to exclude clinically-important CAD. A positive stress myocardial CT perfusion added to coronary CT angiography, stress cardiac MR, and PET have a higher test performance to identify patients requiring invasive coronary artery evaluation.
\end{abstract}

(c) 2019 Elsevier B.V. All rights reserved.

\section{Introduction}

Coronary artery disease (CAD) is a major cause of mortality and morbidity and consumes a sizeable proportion of health care spending [1]. Guidelines recommend diagnostic strategies based on the pre-test likelihood of CAD [2,3].

Several non-invasive anatomical techniques such as coronary computed tomography (CT) angiography as well as functional imaging

\footnotetext{
* Corresponding author. Via C. Parea 4, 20138, Milan, Italy

E-mail address: gianluca.pontone@ccfm.it (G. Pontone).

1 These authors contributed equally to the manuscript.
}

techniques including stress echocardiography (Echo), stress singlephoton emission computed tomography (SPECT), stress cardiac magnetic resonance (CMR) and positron emission tomography (PET) are used to predict the presence of CAD and guide the use of invasive coronary angiography (ICA) $[2,4,5]$ '. More recently, fractional flow reserve derived from coronary $\mathrm{CT}$ angiography $\left(\mathrm{FFR}_{\mathrm{CT}}\right)$ and stress myocardial $\mathrm{CT}$ perfusion have emerged to provide both anatomical and functional evaluation of CAD simultaneously [6,7].

Previous meta-analyses have evaluated the diagnostic test performance of each of these non-invasive anatomical and/or functional imaging modalities compared to ICA and, less commonly, to invasive FFR [8-14]. However, a systematic comparison of all non-invasive 


\begin{tabular}{ll}
\hline Abbreviations \\
CMR & cardiac magnetic resonance \\
CT & computed tomography \\
Echo & echocardiography \\
FFR & fractional flow reserve \\
FFRCT & fractional flow reserve derived from coronary com- \\
& puted tomography angiography \\
ICA & invasive coronary angiography \\
PCI & percutaneous coronary intervention \\
PET & positron emission tomography \\
SPECT & single-photon emission computed tomography
\end{tabular}

diagnostic strategies, including FFR $_{\mathrm{CT}}$ and stress myocardial CT perfusion has not been performed and is necessary to identify the optimal non-invasive diagnostic technique that can identify patients who would benefit from invasive evaluation. Therefore, we undertook a meta-analysis to identify whether any non-invasive diagnostic modality is sufficiently sensitive and specific to guide use of invasive evaluation for patients with stable CAD.

\section{Methods}

We have reported this meta-analysis according to the Preferred Reporting Items for Systematic Reviews and Meta-analyses (PRISMA) statement [15]. The aim of this study was to evaluate the diagnostic test performance of non-invasive imaging tests (index tests) as compared to invasive FFR (reference standard) to detect functionally significant CAD (outcome). IRB approval is not needed being a meta-analysis.

\subsection{Search strategy and study selection}

MEDLINE (1966 to March 7, 2017), Embase (1988 to March 7, 2017) and reference lists of primary studies and reviews were systematically searched. The search terms are summarized in Table S1 and the eligibility criteria in Table S2 in the Supplement. Two researchers (M.V. and G.P. both $>10$ years of experience in data analysis) reviewed the titles and abstracts of all retrieved citations. Potentially eligible studies were retrieved and examined in full text by the same two researchers. Discordances among researchers were reconciled through consensus.

\subsection{Data extraction}

Data extraction was performed by one reviewer (M.V.) and verified by a second reviewer (G.P.). The following variables were extracted from each study: imaging modality, study population characteristics, pre-test likelihood of CAD, per-patient sample size, per- vessel sample size, age of study population, gender distribution, type of stressor used, type of contrast agent, vendor of index test, scanner technology and type of analysis for index test. For each study, true positive, false positive, true negative and false negative results to detect functionally significant CAD as detected by invasive FFR were extracted. When multiple thresholds of index test were used, the best performing threshold parameter was chosen. All analyses were performed at both the vessel and/or patient level.

Study risks of bias were adjudicated using the Quality Assessment of Diagnostic Accuracy Studies (QUADAS) tool [16] considering 15 different items: spectrum representativity, selection criteria, reference standard, time period between index and reference test, differential verification bias, incorporation bias, description of methodology of index and reference test, index test review bias, diagnostic test review bias, clinical review bias, uninterpretable results reported, explanation for withdrawals and established cut-off point for reference test. Discordances among researchers were reconciled through discussion.

\subsection{Statistical analysis}

For each study, data were extracted to construct $2 \times 2$ tables, which were used to calculate sensitivity, specificity, positive (PLR) and negative likelihood ratios (NLR), and the diagnostic odds ratio (DOR) according to following equation [sensitivity/(1-sensitivity)/ (1-specificity)/specificity], together with corresponding 95\% confidence interval (CI). DOR is a single overall indicator of diagnostic performance and the higher is the DOR value the better is the discriminatory power of the test. The sensitivity and specificity estimates were summarized using random-effects meta-analysis [17]. A bivariate metaanalysis following a random effects model was used to plot a hierarchical summary receiver operating characteristic (HSROC) curve. Heterogeneity among study results was quantified by calculating the $I[2]$ statistic. The degree of heterogeneity was considered low $(I[2]<50 \%)$, moderate $(I[2]=50 \%-75 \%)$, or high $(I[2]>75 \%)[18]$. Evidence of small study effects were assessed graphically using funnel plots and statistically via the Egger test for funnel plot asymmetry [19]. All results were considered significant with a $p$ value $<0.05$. Statistical analysis was performed using the "metaphor" and "mada" packages in R statistical software, version 3.5.3 (R-Foundation for Statistical Computing, Vienna, Austria) and the dedicated meta-analysis software Meta-DiSc version 1.4 (Universidad Complutense, Madrid, Spain) [8].

\section{Results}

3.1. Study selection

A total of 1919 citations were retrieved by searching and 77 studies (20-96) were included (Fig. S1). For all index tests, four or more studies were included.

\subsection{Characteristics of included studies}

The study populations and reference and index test characteristics are described in Table S3, Table S4 in the Supplement. All studies recruited participants prospectively. 38/77 (49\%) studies evaluated patients with suspected CAD, 15/77 (19\%) evaluated patients with known CAD, and 24/77 (31\%) studies evaluated patients with suspected or known CAD. The pre-test likelihood of CAD was intermediate to high in all studies except two in which a low-risk cohort was also included. Studies included between 12 and 281 participants. The mean study age was $63 \pm 3$ years (range 53-73years), while the rate of male patients ranged between $32 \%$ and $89 \%$ (55/62). Detection of functionally important CAD was qualitative in 57 studies, semi-quantitative in 14 studies, and fully quantitative in 6 studies.

Table 1

Outcome summary at vessel level.

\begin{tabular}{|c|c|c|c|c|c|c|c|c|c|c|c|c|}
\hline Index Test & $\begin{array}{l}\text { No. Of } \\
\text { Vessels }\end{array}$ & $\mathrm{TP}$ & TN & FP & FN & Sensitivity & Specificity & NPV & PPV & PLR & NLR & DOR \\
\hline Stress Echo & 360 & 126 & 147 & 37 & 50 & $\begin{array}{l}72 \% \\
(64 \%-78 \%)\end{array}$ & $\begin{array}{l}80 \% \\
(73 \%-85 \%)\end{array}$ & $\begin{array}{l}70 \% \\
(61 \%-78 \%)\end{array}$ & $\begin{array}{l}80 \% \\
(70 \%-91 \%)\end{array}$ & $\begin{array}{l}3.35 \\
(1.71-6.59)\end{array}$ & $\begin{array}{l}0.43 \\
(0.25-0.72)\end{array}$ & $\begin{array}{l}9.62 \\
(3.23-28.70)\end{array}$ \\
\hline Stress SPECT & 1764 & 394 & 943 & 204 & 223 & $\begin{array}{l}64 \% \\
(60 \%-68 \%)\end{array}$ & $\begin{array}{l}82 \% \\
(80 \%-84 \%)\end{array}$ & $\begin{array}{l}70 \% \\
(67 \%-74 \%)\end{array}$ & $\begin{array}{l}78 \% \\
(74 \%-83 \%)\end{array}$ & $\begin{array}{l}3.49 \\
(2.75-4.43)\end{array}$ & $\begin{array}{l}0.44 \\
(0.33-0.58)\end{array}$ & $\begin{array}{l}8.92 \\
(5.57-14.29)\end{array}$ \\
\hline PET & 2045 & 398 & 1377 & 201 & 69 & $\begin{array}{l}85 \% \\
(82 \%-88 \%)\end{array}$ & $\begin{array}{l}87 \% \\
(86 \%-89 \%)\end{array}$ & $\begin{array}{l}85 \% \\
(83 \%-88 \%)\end{array}$ & $\begin{array}{l}86 \% \\
(84 \%-89 \%)\end{array}$ & $\begin{array}{l}7.12 \\
(5.49-9.24)\end{array}$ & $\begin{array}{l}0.15 \\
(0.09-0.27)\end{array}$ & $\begin{array}{l}46.76 \\
(24.61-88.86)\end{array}$ \\
\hline Stress CMR & 2868 & 680 & 1858 & 174 & 156 & $\begin{array}{l}81 \% \\
(79 \%-84 \%)\end{array}$ & $\begin{array}{l}91 \% \\
(90 \%-93 \%)\end{array}$ & $\begin{array}{l}82 \% \\
(80 \%-85 \%)\end{array}$ & $\begin{array}{l}89 \% \\
(86 \%-92 \%)\end{array}$ & $\begin{array}{l}8.74 \\
(6.18-12.38)\end{array}$ & $\begin{array}{l}0.21 \\
(0.16-0.26)\end{array}$ & $\begin{array}{l}51.05 \\
(32.77-79.53)\end{array}$ \\
\hline Coronary CT angiography & 2641 & 671 & 1190 & 684 & 96 & $\begin{array}{l}88 \% \\
(85 \%-90 \%)\end{array}$ & $\begin{array}{l}64 \% \\
(61 \%-66 \%)\end{array}$ & $\begin{array}{l}87 \% \\
(78 \%-95 \%)\end{array}$ & $\begin{array}{l}68 \% \\
(61 \%-74 \%)\end{array}$ & $\begin{array}{l}2.39 \\
(1.51-3.79)\end{array}$ & $\begin{array}{l}0.17 \\
(0.11-0.28)\end{array}$ & $\begin{array}{l}14.81 \\
(8.91-24.61)\end{array}$ \\
\hline Stress Myocardial CT perfusion & 1400 & 372 & 808 & 106 & 114 & $\begin{array}{l}77 \% \\
(73 \%-80 \%)\end{array}$ & $\begin{array}{l}88 \% \\
(86 \%-90 \%)\end{array}$ & $\begin{array}{l}80 \% \\
(75 \%-85 \%)\end{array}$ & $\begin{array}{l}87 \% \\
(82 \%-93 \%)\end{array}$ & $\begin{array}{l}6.61 \\
(3.75-11.67)\end{array}$ & $\begin{array}{l}0.27 \\
(0.19-0.39)\end{array}$ & $\begin{array}{l}32.05 \\
(14.34-71.63)\end{array}$ \\
\hline FFR $_{\mathrm{CT}}$ & 1247 & 345 & 630 & 209 & 63 & $\begin{array}{l}85 \% \\
(81 \%-88 \%)\end{array}$ & $\begin{array}{l}75 \% \\
(72 \%-78 \%)\end{array}$ & $\begin{array}{l}80 \% \\
(73 \%-88 \%)\end{array}$ & $\begin{array}{l}72 \% \\
(65 \%-78 \%)\end{array}$ & $\begin{array}{l}2.82 \\
(1.84-4.33)\end{array}$ & $\begin{array}{l}0.22 \\
(0.16-0.30)\end{array}$ & $\begin{array}{l}15.25 \\
(7.20-32.32)\end{array}$ \\
\hline $\begin{array}{l}\text { Coronary CT angiography+stress } \\
\text { myocardial CT perfusion }\end{array}$ & 1036 & 287 & 609 & 63 & 77 & $\begin{array}{l}79 \% \\
(74 \%-83 \%)\end{array}$ & $\begin{array}{l}91 \% \\
(88 \%-93 \%)\end{array}$ & $\begin{array}{l}81 \% \\
(78 \%-84 \%)\end{array}$ & $\begin{array}{l}90 \% \\
(86 \%-94 \%)\end{array}$ & $\begin{array}{l}9.57 \\
(5.37-17.07)\end{array}$ & $\begin{array}{l}0.23 \\
(0.17-0.33)\end{array}$ & $\begin{array}{l}54.10 \\
(22.57-129.57)\end{array}$ \\
\hline
\end{tabular}

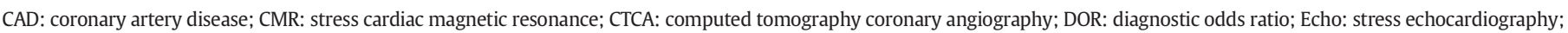

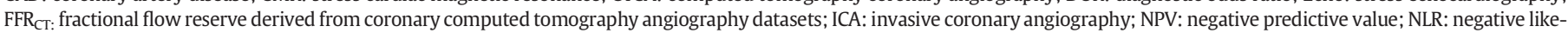
lihood ratio; PET: positron emission tomography; PLR: positive likelihood ratio; PPV: positive predictive value; SPECT: single-photon emission computed tomography. 
Table 2

Outcome summary at patient level.

\begin{tabular}{|c|c|c|c|c|c|c|c|c|c|c|c|c|}
\hline Index Test & $\begin{array}{l}\text { No. Of } \\
\text { Patients }\end{array}$ & $\mathrm{TP}$ & $\mathrm{TN}$ & FP & FN & Sensitivity & Specificity & NPV & PPV & PLR & NLR & DOR \\
\hline Stress Echo & 361 & 106 & 164 & 31 & 60 & $\begin{array}{l}64 \% \\
(56 \%-71 \%)\end{array}$ & $\begin{array}{l}84 \% \\
(78 \%-89 \%)\end{array}$ & $\begin{array}{l}70 \% \\
(64 \%-76 \%)\end{array}$ & $\begin{array}{l}81 \% \\
(74 \%-88 \%)\end{array}$ & $\begin{array}{l}3.51 \\
(2.53-4.87)\end{array}$ & $\begin{array}{l}0.45 \\
(0.35-0.57)\end{array}$ & $\begin{array}{l}11.09 \\
(6.31-19.48)\end{array}$ \\
\hline Stress SPECT & 682 & 224 & 289 & 78 & 91 & $\begin{array}{l}71 \% \\
(66 \%-76 \%)\end{array}$ & $\begin{array}{l}79 \% \\
(74 \%-83 \%)\end{array}$ & $\begin{array}{l}70 \% \\
(65 \%-75 \%)\end{array}$ & $\begin{array}{l}75 \% \\
(69 \%-80 \%)\end{array}$ & $\begin{array}{l}2.94 \\
(1.96-4.40)\end{array}$ & $\begin{array}{l}0.42 \\
(0.28-0.62)\end{array}$ & $\begin{array}{l}7.99 \\
(3.69-17.30)\end{array}$ \\
\hline PET & 609 & 207 & 321 & 52 & 29 & $\begin{array}{l}88 \% \\
(83 \%-92 \%)\end{array}$ & $\begin{array}{l}86 \% \\
(82 \%-89 \%)\end{array}$ & $\begin{array}{l}88 \% \\
(84 \%-92 \%)\end{array}$ & $\begin{array}{l}85 \% \\
(82 \%-89 \%)\end{array}$ & $\begin{array}{l}6.35 \\
(4.45-9.07)\end{array}$ & $\begin{array}{l}0.13 \\
(0.06-0.28)\end{array}$ & $\begin{array}{l}51.79 \\
(18.46-145.33)\end{array}$ \\
\hline Stress CMR & 1085 & 476 & 474 & 66 & 69 & $\begin{array}{l}87 \% \\
(84 \%-90 \%)\end{array}$ & $\begin{array}{l}88 \% \\
(85 \%-90 \%)\end{array}$ & $\begin{array}{l}86 \% \\
(84 \%-88 \%)\end{array}$ & $\begin{array}{l}86 \% \\
(84 \%-89 \%)\end{array}$ & $\begin{array}{l}6.65 \\
(5.30-8.34)\end{array}$ & $\begin{array}{l}0.15 \\
(0.12-0.19)\end{array}$ & $\begin{array}{l}49.36 \\
(33.73-72.25)\end{array}$ \\
\hline Coronary CT angiography & 1478 & 587 & 358 & 488 & 45 & $\begin{array}{l}93 \% \\
(91 \%-95 \%)\end{array}$ & $\begin{array}{l}42 \% \\
(39 \%-46 \%)\end{array}$ & $\begin{array}{l}93 \% \\
(85 \%-100 \%)\end{array}$ & $\begin{array}{l}62 \% \\
(57 \%-66 \%)\end{array}$ & $\begin{array}{l}1.72 \\
(1.35-2.18)\end{array}$ & $\begin{array}{l}0.17 \\
(0.10-0.30)\end{array}$ & $\begin{array}{l}10.84 \\
(5.85-20.07)\end{array}$ \\
\hline Stress myocardial CT perfusion & 410 & 177 & 163 & 23 & 47 & $\begin{array}{l}79 \% \\
(73 \%-84 \%)\end{array}$ & $\begin{array}{l}88 \% \\
(82 \%-92 \%)\end{array}$ & $\begin{array}{l}81 \% \\
(74 \%-88 \%)\end{array}$ & $\begin{array}{l}84 \% \\
(77 \%-91 \%)\end{array}$ & $\begin{array}{l}5.15 \\
(2.22-11.92)\end{array}$ & $\begin{array}{l}0.26 \\
(0.16-0.42)\end{array}$ & $\begin{array}{l}28.56 \\
(15.50-52.62)\end{array}$ \\
\hline FFRct & 664 & 263 & 257 & 116 & 28 & $\begin{array}{l}90 \% \\
(86 \%-94 \%)\end{array}$ & $\begin{array}{l}69 \% \\
(64 \%-74 \%)\end{array}$ & $\begin{array}{l}86 \% \\
(76 \%-96 \%)\end{array}$ & $\begin{array}{l}70 \% \\
(62 \%-79 \%)\end{array}$ & $\begin{array}{l}2.68 \\
(1.66-4.34)\end{array}$ & $\begin{array}{l}0.16 \\
(0.11-0.23)\end{array}$ & $\begin{array}{l}20.22 \\
(10.70-38.22)\end{array}$ \\
\hline $\begin{array}{l}\text { Coronary CT angiography }+ \text { stress } \\
\text { myocardial CT perfusion }\end{array}$ & 248 & 132 & 84 & 17 & 15 & $\begin{array}{l}89 \% \\
(84 \%-94 \%)\end{array}$ & $\begin{array}{l}83 \% \\
(74 \%-90 \%)\end{array}$ & $\begin{array}{l}88 \% \\
(82 \%-93 \%)\end{array}$ & $\begin{array}{l}83 \% \\
(78 \%-88 \%)\end{array}$ & $\begin{array}{l}4.72 \\
(2.60-8.57)\end{array}$ & $\begin{array}{l}0.13 \\
(0.08-0.21)\end{array}$ & $\begin{array}{l}45.50 \\
(19.62-105.54)\end{array}$ \\
\hline
\end{tabular}

For abbreviations see Table 1.

\subsection{Quality of included studies}

Fig. S2 displays the study risks of bias according to the QUADAS-2 score. The patient selection was appropriate in 70 out of 77 studies (91\%) and all patients received the reference standard with an established cut-off point between index and reference test.

\subsection{Diagnostic test accuracy}

The forest plots for each test presenting pooled sensitivity and specificity are shown in vessel-based (Figs. S3a and b) and patient-based analysis (Fig. S4) in the Supplement and in the manuscript, respectively. The overall diagnostic test performance of each non-invasive test is shown in Table 1 (vessel analysis) and Table 2 (participant-level analysis).

The sensitivity of non-invasive evaluations to detect functionally significant coronary lesion in descending order was: coronary CT angiography [88\%(85\%-90\%)], FFR $_{\text {CT }}[85 \%(81 \%-88 \%)]$, PET [85\%(82\%-88\%)], stress CMR [81\%(79\%-84\%)], the combination of stress myocardial CT perfusion combined with coronary CT angiography [79\%(74\%-83\%)], stress myocardial CT perfusion alone [77\%(73\%-80\%)], stress Echo [72\%(64\%-78\%)], and stress SPECT [64\%(60\%-68\%)] (Table 1). Specificity was highest for stress myocardial CT perfusion added to coronary CT angiography [91\%(88\%93\%)], or stress CMR alone [91\%(90\%-93\%)], and PET [87\%(86\%-89\%)]with lower specificity for $\mathrm{FFR}_{\mathrm{CT}}[75 \%(72 \%-78 \%)]$ and coronary CT angiography alone [64\%(61\%66\%)] (Table 1).

The participant-based sensitivity in descending order was: coronary CT angiography [93\%(91\%-95\%)], FFR CT $[90 \%(86 \%-94 \%)]$, coronary CT angiography combined with stress myocardial CT perfusion [89\%(84\%-94\%)], PET [88\%(83\%-92\%)], stress CMR [87\%(84\%$90 \%)$, stress myocardial CT perfusion alone [79\%(73\%-84\%)], stress SPECT [71\%(66\%$76 \%)]$, and stress Echo [64\%(56\%-71\%)] (Table 2). Specificity to rule out CAD was highest for stress myocardial CT perfusion alone [88\%(82\%-92\%)], followed by (in descending order) stress CMR [88\%(85\%-90\%)], PET [86\%(82\%-89\%)], stress Echo [84\%(78\%-89\%)], stress SPECT [79\%(74\%-83\%)], FFR CT $[69 \%(64 \%-74 \%)]$, and coronary CT angiography alone $[42 \%(39 \%-46 \%)]$ (Table 2$)$.

HSROC curve analyses for vessel-based and participant-based models are shown in Fig. S5 in the Supplement and in Fig. 1. Positron emission tomography, stress CMR, stress myocardial CT perfusion, and coronary CT angiography combined with stress myocardial CT perfusion demonstrated the highest area under the curve in both models together with the highest DOR, while stress Echo, coronary CT angiography and stress SPECT demonstrated lower but similar performance in both per-vessel and per-patient models with an area under the curve ranging between $80-85 \%$ and $80-82 \%$, respectively.

The Funnel plot showing the publication bias evaluated by Egger test for plot asymmetry in a vessel-based model and patient-based model are shown in Fig. S6 and Fig. S7 in the Supplement, respectively. In a patient-based model, the largest change in post-test probability was observed for a negative coronary CT angiography and for positive stress CMR, PET, and stress myocardial CT perfusion (Fig. 2).

The heterogeneity between studies was low or absent for stress Echo ( $\mathrm{I}[2]=14.1 \%)$, stress CMR $(0.0 \%), \mathrm{FFR}_{\mathrm{CT}}(0.0 \%)$, coronary $\mathrm{CT}$ angiography + stress myocardial CT perfusion $(0.0 \%)$, moderate for PET (73.5\%), coronary CT angiography $(53.4 \%)$, stress myocardial CT perfusion (66.0\%), and high for stress SPECT (78.6\%) (Table S5).

\section{Discussion}

In this systematic review of diagnostic test performance for noninvasive coronary artery evaluation being invasive FFR [97] the reference standard, a coronary CT angiography showed the highest sensitivity while stress CMR and the combination of coronary CT angiography plus stress myocardial CT perfusion showed the highest specificity in a vessel based-model. Similarly, in a patient-based model, coronary CT angiography still showed the highest sensitivity, while the highest specificity was reached by PET, stress CMR and stress myocardial CT perfusion.

The largest incremental change in pre-to post-test probability of disease occurred with a negative coronary $\mathrm{CT}$ angiography to rule out disease and with positive stress CMR, stress myocardial CT perfusion, or PET indicating patients who would most likely benefit from invasive coronary evaluation.

Despite the partial overlap of the confidence intervals of sensitivity and specificity relatively to each technique, the results of our analysis allow to inform a putative sequential diagnostic approach for patients who are at moderate risk of functionally significant coronary lesion. The first step is to identify patients who have low risk of functionally significant coronary lesion and who may not benefit from invasive assessment. In this setting, negative coronary CT angiography could safely rule-out the disease at patient-level identifying the subject who does not need further evaluation [98]. If a coronary CT angiography is positive, the need for additional testing could be desiderable [99]. Therefore, in the setting of a positive coronary CT angiography, the second step could be FFR $\mathrm{CT}_{\mathrm{C}}$ that raises the post-test probability of disease without the need of other procedures, radiation exposure, and contrast administration and provided a better selection of patients with functionally significant CAD. However, it is important to underline that at moment clinically approved $\mathrm{FFR}_{\mathrm{CT}}$ is provided by a single company and it is expensive. Despite this, the recent multicenter trial PLATFORM showed that a diagnostic strategy based on FFR $_{\mathrm{CT}}$ was associated with a $61 \%$ reduction of invasive coronary angiography and a $32 \%$ reduction of overall cost [100] as compared to a standard diagnostic strategy also including in the economic model the individual cost of FFR $_{\mathrm{CT}}$ analysis. A negative FFR $_{\mathrm{CT}}$ could rule out hemodynamically significant CAD with a single CT acquisition. However, in case of a positive $\mathrm{FFR}_{\mathrm{CT}}$, the post-test probability is lower as compared to stress CMR, stress myocardial CT perfusion or PET that could be considered a useful test on top of FFR $\mathrm{CT}_{\mathrm{T}}$ thanks to 
stress Echo

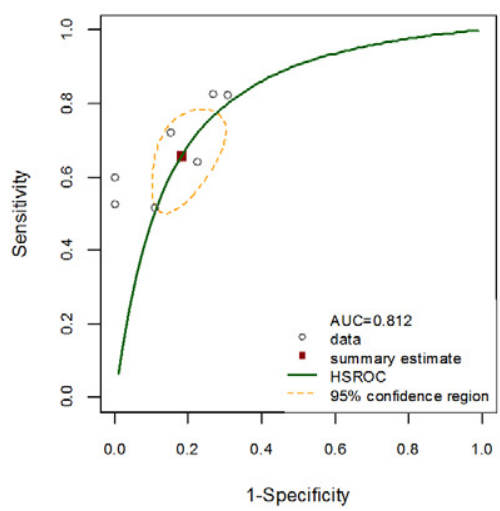

coronary $\mathrm{CT}$ angiography

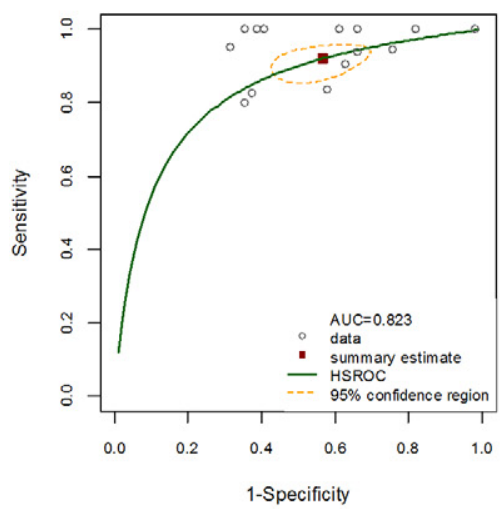

stress myocardial CT perfusion

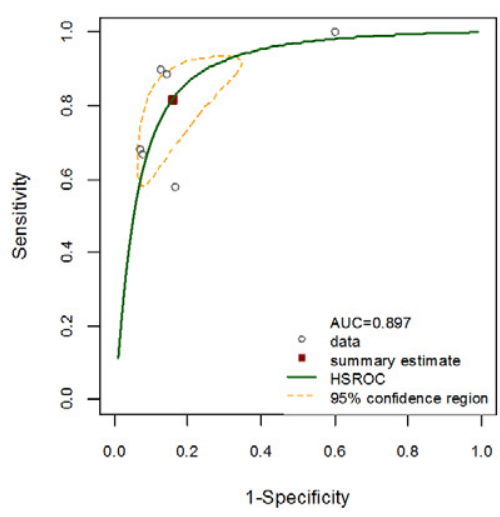

stress CMR

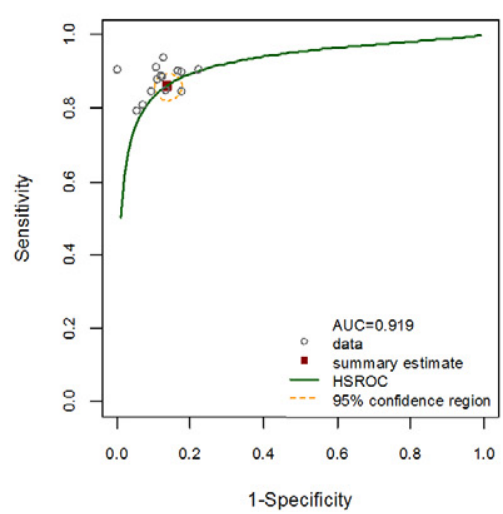

stress SPECT

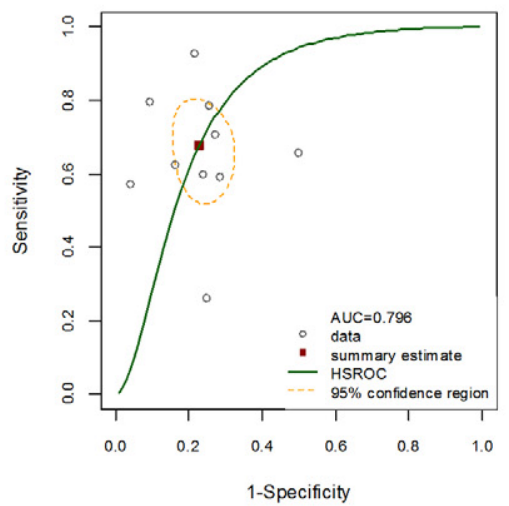

FFRct

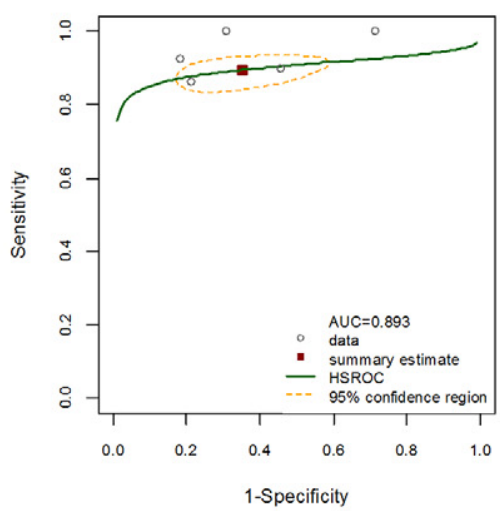

coronary $\mathrm{CT}$ angiography + stress myocardial $\mathrm{CT}$ perfusion

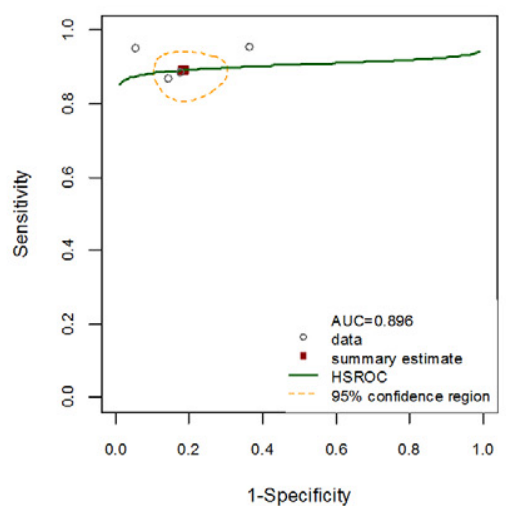

PET

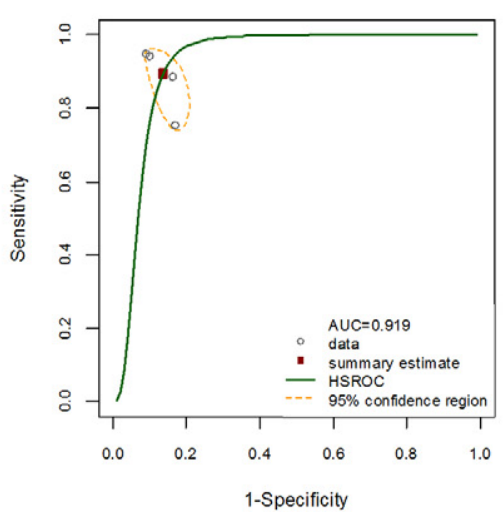


their excellent specificity at vessel-level that allows to identify the lesions that should be investigated and eventually revascualrized.

In summary, with this approach, the majority of patients should be evaluated with coronary CT angiography alone with a minority of them with the addition of $\mathrm{FFR}_{\mathrm{CT}}$ on top and with a small number of patients further evaluated with stress perfusion tests.

The findings of this analysis may provide additional information as compared with previous research, by including a broader range of non-invasive diagnostic test [8-14]. In particular, Danad et al. [15] performed a similar meta-analysis reporting that stress CMR had the highest performance for diagnosis of ischemia-causing CAD, with lower performance for stress Echo and stress SPECT. However, some additional information are present in our study. First, they did not included PET, stress myocardial CT perfusion, and the combination of coronary CT angiography plus stress myocardial CT perfusion that in our study showed very high AUC and DOR, reflecting tests with higher discriminatory power. This evidence is of note considering the lower cost of stress myocardial CT perfusion as compared for example to FFR $_{\mathrm{CT}}$ or PET and the shorter time delay for image analysis as compared to FFR $_{\mathrm{CT}}$. Finally, while the meta-analysis of Danad et al. included also retrospective studies with the risk of referral bias to invasive evaluation, in our study the majority of reports were all prospective. Moreover, Danad et al. included only studies in which the invasive FFR was performed in all vessels with a minimal requirement of at least $75 \%$ of the coronary vessels. This reinforce the robustness of this study but with the risk to miss some robust papers in which invasive FFR was just applied in the intermediate lesions according to clinical practice as performed in our metanalysis.

\section{Limitations}

Limitations in our meta-analysis should be considered when interpreting the findings. First, we included studies that used different diagnostic thresholds to define anatomical stenosis and pathologic invasive FFR [101]. Second, results may be biased by the fact that they were obtained in centers with sound experience in advanced imaging modalities and may not be generalizable to many real-world practices. However, our analysis included only prospective studies. Third, we should take in consideration that when invasive FFR is used as the reference standard for ischemia, the technique is able to assess myocardial ischemia due to epicardial coronary lesions only. On the other side, a meticulous process to verify the correct co-registration of defined perfusion defects at stress test with culprit vessels as defined by invasive FFR is not always performed in the study and this could be responsible for a reduced location-specific accuracy of stress tests. Fourth, the patients enrolled in the studies could have had different pre-test likelihoods of CAD that may potentially affect the diagnostic performance of each imaging modality. Fifth, to date there is no standard stress CT perfusion protocol available for use. Moreover, stress CT perfusion techniques are affected by beam-hardening artifacts that are partially attenuated by dualenergy sources. Unfortunately, no studies included in our metaanalysis used this technology. In this regard, the results of the ongoing DECIDE Gold prospective multicenter trial [102] comparing dualenergy stress CT perfusion vs. invasive FFR are awaited. Sixth, this analysis does not take in account many of the most pressing issues we face in clinical practice such as obese patients, arrhythmic patients, high calcium burden, kidney dysfunction, and implanted cardiac devices. Unfortunately, the analysis of these factors, including radiant exposure and costs, requires a cooperative meta-analysis in which individual variables are shared and this is not part of our methodology. Therefore, further specific meta-analysis focused on these specific topics would be desirable.

Sixth, in contrast to combining summary estimates aggregated from different publications such as in our study, investigators have begun to collaborate to combine individual patient-level data and perform a pooled analysis. This approach has several distinct advantages, most notably in greatly increasing the power to examine variations in treatment outcomes according to patient characteristics. However, despite this approach has several advantegs, is still not widespread due to some key barriers. Indeed, a recent statement of American Heart Association showed how only $11 \%$ of metaanalysis published in the field of cardiovascular diseases are designed as individual patient-level data studies [103]. Therefore, our metanalysis can be still considered acceptable from methodological point of view.

\section{Conclusions}

In conclusion, a negative coronary $\mathrm{CT}$ angiography should be the best ruler-out to exclude clinically-important CAD, while a positive stress myocardial CT perfusion added to coronary CT angiography, stress cardiac MR alone or PET seem to be associated with a better test performance to identify patients requiring invasive coronary artery evaluation. These suggest a coronary CT angiography might be a firstline diagnostic test to assess for CAD in a patient with moderate pre-

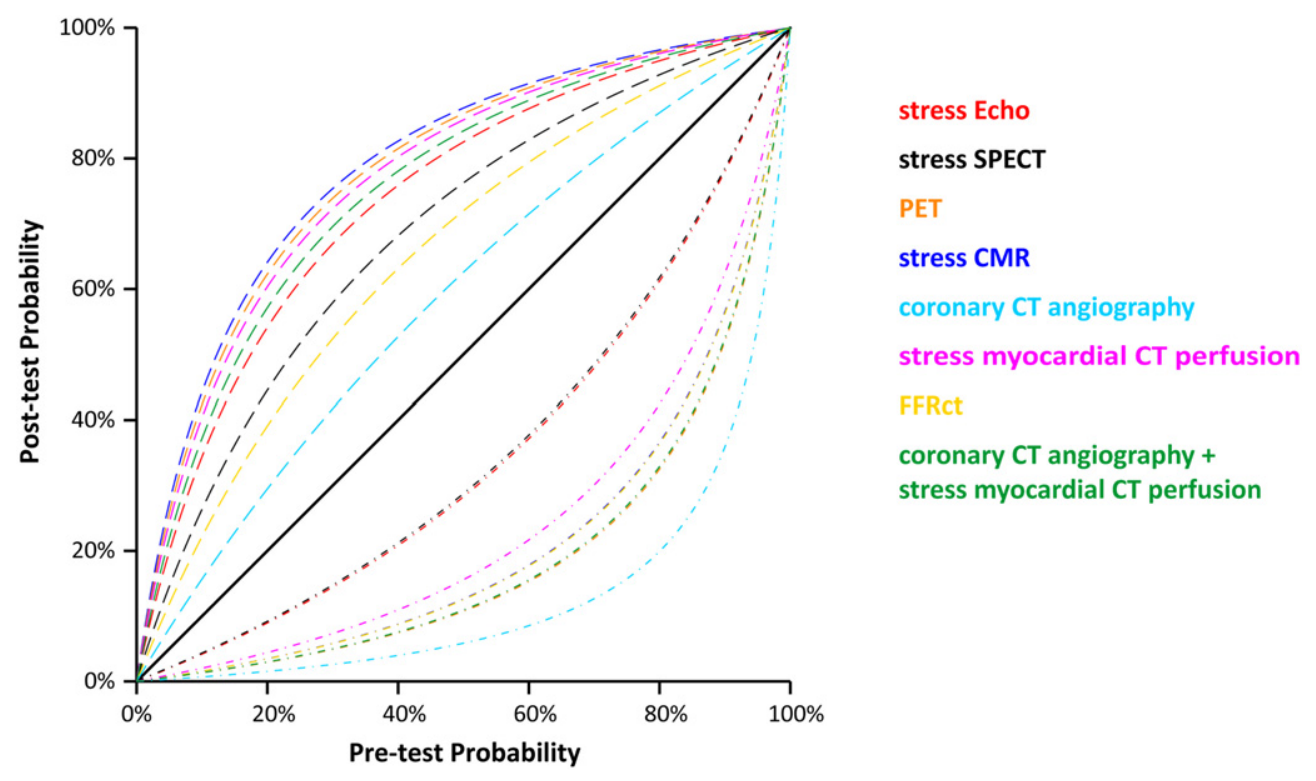

Fig. 2. Change in post-test probability of hemodynamically significant CAD by various pretest probabilities. For abbreviations see Fig. 1 . 
test probability. In patients with a positive coronary CT angiography, FFR $_{\mathrm{CT}}$ increases the specificity of detecting patients who may benefit from invasive evaluation. Further metaanalysis based on individual patient data collectioin and/or prospective studies are needed to validate the accuracy, safety, and cost-effectiveness of this diagnostic algorithm in patients with suspected CAD. Moreover, further studies should be addressed to test the performance of non-invasive imaging modalitis in the specific setting of patients with previous history of revascularization.

\section{Funding/support}

SCP received a Rutherford Discovery Fellowship from the Royal Society of New Zealand. Other authors received no funding sources.

\section{Conflict of interest disclosures}

GP received institutional grant and fee from GE Healthcare, Medtronic, Bracco, Heartflow; DA received institutional grant and fee from GE Healthcare. Other authors have no disclosures.

\section{Acknowledgments}

Author Contributions: GP had full access to all of the data in the study and takes responsibility for the integrity of the data and the accuracy of the data analysis. GP and AIG contributed equally to the manuscript. Concept and design: GP,AIG,MV,SCP,GS. Acquisition, analysis, or interpretation of data: GP,AIG,DA,MV,MR,FC. Drafting of the manuscript: GP,AIG,SCP,GS. Critical revision of the manuscript for important intellectual content: All authors. Statistical analysis: LF,VL. Administrative, technical, or material support: MV. Study supervision: GP and AIG.

\section{Appendix A. Supplementary data}

Supplementary data to this article can be found online at https://doi. org/10.1016/j.ijcard.2019.10.046.

\section{References}

[1] F.L. Lucas, M.A. DeLorenzo, A.E. Siewers, D.E. Wennberg, Temporal trends in the utilization of diagnostic testing and treatments for cardiovascular disease in the United States 1993-2001, Circulation 113 (2006) 374-379.

[2] ESC guidelines on the management of stable coronary artery disease: the Task Force on the management of stable coronary artery disease of the European Society of Cardiology, Eur. Heart J. 34 (2013) 2949-3003.

[3] ACCF/SCAI/AATS/AHA/ASE/ASNC/HFSA/HRS/SCCM/SCCT/SCMR/STS 2012 appropriate use criteria for diagnostic catheterization, J. Am. Coll. Cardiol. 59 (2012) 1995-2027.

[4] M.R. Patel, D. Dai, A.F. Hernandez, P.S. Douglas, J. Messenger, K.N. Garratt, et al. Prevalence and predictors of nonobstructive coronary artery disease identified with coronary angiography in contemporary clinical practice, Am. Heart J. 167 (2014) 846-852.

[5] N. Gaibazzi, T. Porter, V. Lorenzoni, V. Lorenzoni, G. Pontone, D. De Santis, et al., Effect of coronary revascularization on the prognostic value of stress myocardial contrast wall motion and perfusion imaging, J. Am. Heart Assoc. 6 (6) (2017) https:// doi.org/10.1161/JAHA.117.006202.

[6] G. Pontone, D. Andreini, A.I. Guaricci, M. Guglielmo, S. Mushtaq, A. Baggiano, et al. Rationale and design of the PERFECTION (comparison between stress cardiac computed tomography PERfusion versus Fractional flow rEserve measured by Computed Tomography angiography in the evaluation of suspected cOroNary artery disease) prospective study, J. Cardiovasc. Comput. Tomogr. 10 (2016) 330-334.
[7] G. Pontone, D. Andreini, A. Baggiano, E. Bertella, S. Mushtaq, E. Conte, et al., Functional relevance of coronary artery disease by cardiac magnetic resonance and cardiac computed tomography: myocardial perfusion and fractional flow reserve, BioMed Res. Int. 2015 (2015) 297696.

[8] R.A. Takx, B.A. Blomberg, H. El Aidi, H. El Aidi, J. Habets, P.A. de Jong, et al., Diagnostic accuracy of stress myocardial perfusion imaging compared to invasive coronary angiography with fractional flow reserve meta-analysis, Circ. Cardiovasc. Imag. 8 (2015) https://doi.org/10.1161/CIRCIMAGING.114.002662.

[9] J.A. Gonzalez, M.J. Lipinski, L. Flors, P.W. Shaw, C.M. Kramer, M. Salerno, et al., Meta-analysis of diagnostic performance of coronary computed tomography angiography, computed tomography perfusion, and computed tomography-fractional flow reserve in functional myocardial ischemia assessment versus invasive fractional flow reserve, Am. J. Cardiol. 116 (2015) 1469-1478.

[10] L. Chen, X. Wang, J. Bao, C. Geng, Y. Xia, J. Wang, Direct comparison of cardiovascular magnetic resonance and single-photon emission computed tomography for detection of coronary artery disease: a meta-analysis, PLoS One 9 (2014) e88402.

11] C. Jaarsma, T. Leiner, S.C. Bekkers, H.J. Crijns, J.E. Wildberger, E. Nagel, et al., Diagnostic performance of noninvasive myocardial perfusion imaging using singlephoton emission computed tomography, cardiac magnetic resonance, and positron emission tomography imaging for the detection of obstructive coronary artery disease: a meta-analysis, J. Am. Coll. Cardiol. 59 (2012) 1719-1728.

[12] A.Y. Tashakkor, S. Nicolaou, J. Leipsic, G.B. Mancini, The emerging role of cardiac computed tomography for the assessment of coronary perfusion: a systematic review and meta-analysis, Can. J. Cardiol. 28 (2012) 413-422.

[13] M. Hamon, G. Fau, G. Nee, J. Ehtisham, R. Morello, Meta-analysis of the diagnostic performance of stress perfusion cardiovascular magnetic resonance for detection of coronary artery disease, J. Cardiovasc. Magn. Reson. 12 (2010) 29.

[14] I. Danad, J. Szymonifka, J.W.R. Twisk, B.L. Norgaard, C.K. Zarins, P. Knaapen, et al., Diagnostic performance of cardiac imaging methods to diagnose ischaemia-causing coronary artery disease when directly compared with fractional flow reserve as a reference standard: a meta-analysis, Eur. Heart J. 38 (2017) 991-998.

[15] D. Liberati Moher, A. Liberati, J. Tetzlaff, D.G. Altman, PRISMA Group, Preferred reporting item for systematic reviews and meta-analyses: the PRISMA statement, BMJ 339 (2009) b2535.

[16] P. Whiting, A.W. Rutjes, J.B. Reitsma, P.M. Bossuyt, J. Kleijnen, The development of QUADAS: a tool for the quality assessment of studies of diagnostic accuracy included in systematic reviews, BMC Med. Res. Methodol. 3 (2003) 25

[17] R. DerSimonian, N. Laird, et al., Meta-analysis in clinical trials, Control, Clin. Trials 7 (1986) 177-188

[18] J.P. Higgins, S.G. Thompson, J.J. Deeks, D.G. Altman, Measuring inconsistency in meta-analyses, BMJ 327 (2003) 557-560.

[19] Regression methods to detect publication and other bias in meta-analysis, in: H.R. Rothstein, A.J. Sutton, M. Borenstein (Eds.),Publication Bias in Meta-Analysis: Prevention, Assessment, and Adjustments, vol. 99, 2005, p. 110.

[97] B. De Bruyne, N.H. Pijls, B. Kalesan, B. Kalesan, E. Barbato, P.A. Tonino, et al., FAME 2 Trial Investigators. Fractional flow reserve-guided PCI versus medical therapy in stable coronary disease, N. Engl. J. Med. 367 (2012) 991-1001.

[98] B. Bittencourt, E.A. Hulten, V. Veeranna, R. Blankstein, Coronary computed tomography angiography in the evaluation of chest pain of suspected cardiac origin, Circulation 133 (2016) 1963-1968.

[99] G. Pontone, E. Bertella, S. Mushtaq, M. Loguercio, S. Cortinovis, A. Baggiano, et al., Coronary artery disease: diagnostic accuracy of CT coronary angiography-A comparison of high and standard spatial resolution scanning, Radiology 271 (2014) 688-694.

[100] M.A. Hlatky, B. De Bruyne, G. Pontone, M.R. Patel, B.L. Norgaard, R.A. Byrne, et al. PLATFORM investigators. Quality-of-Life and economic outcomes of assessing fractional flow reserve with computed tomography angiography: PLATFORM, J. Am. Coll. Cardiol. 66 (2015) 2315-2323.

[101] C.M. Cook, R. Petraco, M.J. Shun-Shin, Y. Ahmad, S. Nijjer, R. Al-Lamee, et al., Diagnostic accuracy of computed tomography-derived fractional flow reserve: a systematic review, JAMA Cardiol 2 (2017) 803-810.

[102] Q.A. Truong, P. Knaapen, G. Pontone, D. Andreini, J. Leipsic, P. Carrascosa, et al, Rationale and design of the dual-energy computed tomography for ischemia determination compared to "gold standard" non-invasive and invasive techniques (DECIDE-Gold): a multicenter international efficacy diagnostic study of reststress dual-energy computed tomography angiography with perfusion, J. Nucl. Cardiol. 22 (2015) 1031-1040.

[103] G. Rao, F. Lopez-Jimenez, J. Boyd, F. D'Amico, N.H. Durant, M.A. Hlatky, et al., Methodological standards for meta-analyses and qualitative systematic reviews of cardiac prevention and treatment studies: a scientific statement from the American Heart association, Circulation 136 (2017) e172-e194. 